ORIGINAL ARTICLE

\title{
"The joy to bless and to relieve mankind": child healthcare at Northampton General Infirmary 1744
}

\section{A N Williams}

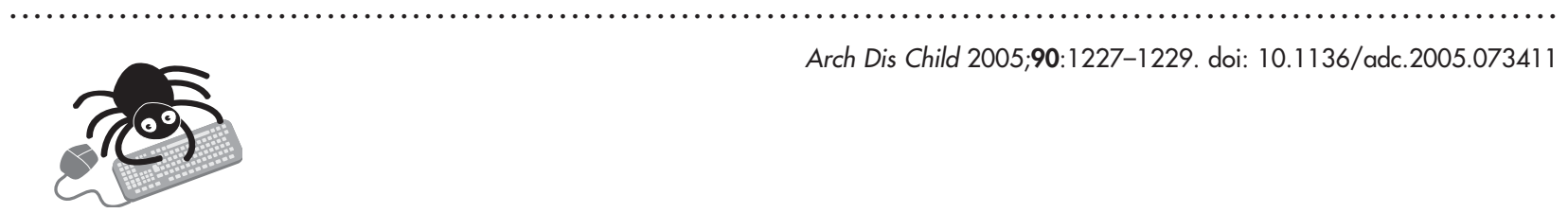

Supplementary material is available on the $A D C$ website (http:// www.archdischild.com/ supplemental)

For more than a century before the opening of Great Ormond Street Hospital for Children (1852), children in England were treated and even admitted in voluntary hospitals in spite of rules prohibiting such care. The earliest English eighteenth century records, that contain the patient's age, are held in Northampton. Reviewing records from the Northampton General Infirmary (from 1903 the Northampton General

Correspondence to: Dr A N Williams, Child Development Centre, Northampton General Hospital, Northampton NN1 5BD, UK; anw@ doctors.org.uk

Accepted 21 June 2005 Hospital) for the period 1744-45 gives a flavour of hospital child health care in an era before the formal recognition of paediatrics as a medical specialty and the construction of specialist provision. Indeed the first patient admitted to the Northampton General Infirmary on 29 March 1744 was Thomasin Grace, a 13 year old child.

In Northampton, in its first year of operation, children as young as 2 years of age were seen in outpatients and from 8 years were admitted. Paediatric cases up to and including those 16 years of age made up 26\% of the number of patients seen for that year. Within the first year of opening for children of 10 years of age and under, there were eight inpatient admissions and 18 children were treated in outpatients.

$\mathrm{n}$ 1700 there were very few hospitals in England, using the modern sense of the word as a place of medical care and treatment. The first English hospitals were in London, most notably St Bartholomew's Hospital, which was refounded in 1544.

The enlightenment of the eighteenth century saw an increasing social awareness driven initially through the works of the physician/philosopher John Locke (16321704). Running alongside this process was the development of a provincial hospital movement, which led to the founding of 35 voluntary hospitals in England and seven in Scotland during this century. The first such hospitals were opened in Winchester (in 1736) and Bristol (in 1737). ${ }^{1-3}$ Northampton opened in 1744 and was the sixth.

These hospitals were created by and dependent on public subscription. ${ }^{4}$ Set up entirely independent of government legislation, they were the main source of medical care for the poor, and mainly saw adults.

Any access to child health in the eighteenth century was limited to the rich few who could afford access to a private physician. The London Foundling Hospital (1745) and George Armstrong's short lived Dispensary for the Infant Poor (1769-81) both laid the foundations and foreshadowed future nineteenth century developments in child health care, but their benefits were local and limited. ${ }^{5}$

\section{THE NORTHAMPTON GENERAL INFIRMARY}

Northampton is one of the oldest towns in England. In 1726, Daniel Defoe wrote in his A Tour through the whole Islands of Great Britain that Northampton was "the handsomest and best built town in all this part of England". Its first hospital, St John's Hospital (an almshouse), was founded in 1138 but closed with the dissolution of the monasteries in the sixteenth century. Northampton was very much smaller than today, having a population of 5136 in $1744,{ }^{6}$ rising to 7020 in $1801 .{ }^{7}$

The driving force for the creation of a hospital in Northampton was Dr (later Sir) James Stonhouse who arrived in Northampton in 1743 and by that July had printed and circulated papers advocating for an infirmary. ${ }^{8}$ Later that year he published "Consideration for the establishment of a county hospital". He was supported in this by his friend the Rev. Dr P Doddridge, who preached an inspiring sermon in September of that year, which made a great impression and was later published.

Thus Northampton was moved to establish an infirmary for the benefit of "the poor, sick, and lame".

For Northampton the subscription list's aim was to defray "the necessary expense of an infirmary at Northampton for the benefit of the poor sick of the county of Northampton, who shall be recommended by any of the subscribers or benefactors"..

The public campaign also included an anonymous poem, "The Progress of Charity Occasion'd by reading the Proposals for Establishing a Country Hospital at Northampton", published on 15 August 1743, with the stirring verse:

\section{"Northampton's self the Pleasing Task shall claim, \\ To fix her in the town that bears his name. \\ And Tit''d Power its Noblest use shall find, \\ The joy to Bless and to Relieve Mankind."}

The subscription was a success and Northampton Infirmary opened on Thursday, 29 March 1744, having 30 beds.

Ten patients were admitted on its first day, 29 March 1744, the first being Thomasin Grace, a 13 year old girl, whose admission record states she had a "scald head" which she had had "from her infancy". One can speculate that this was severe eczema exacerbated through chronic infection. Whatever the condition she was discharged cured on 7 July. ${ }^{7}$

Admissions were mainly for social reasons, malnutrition, exposure, with some chronic medical problem. This admission was not necessarily on the ground of absolute need as the 


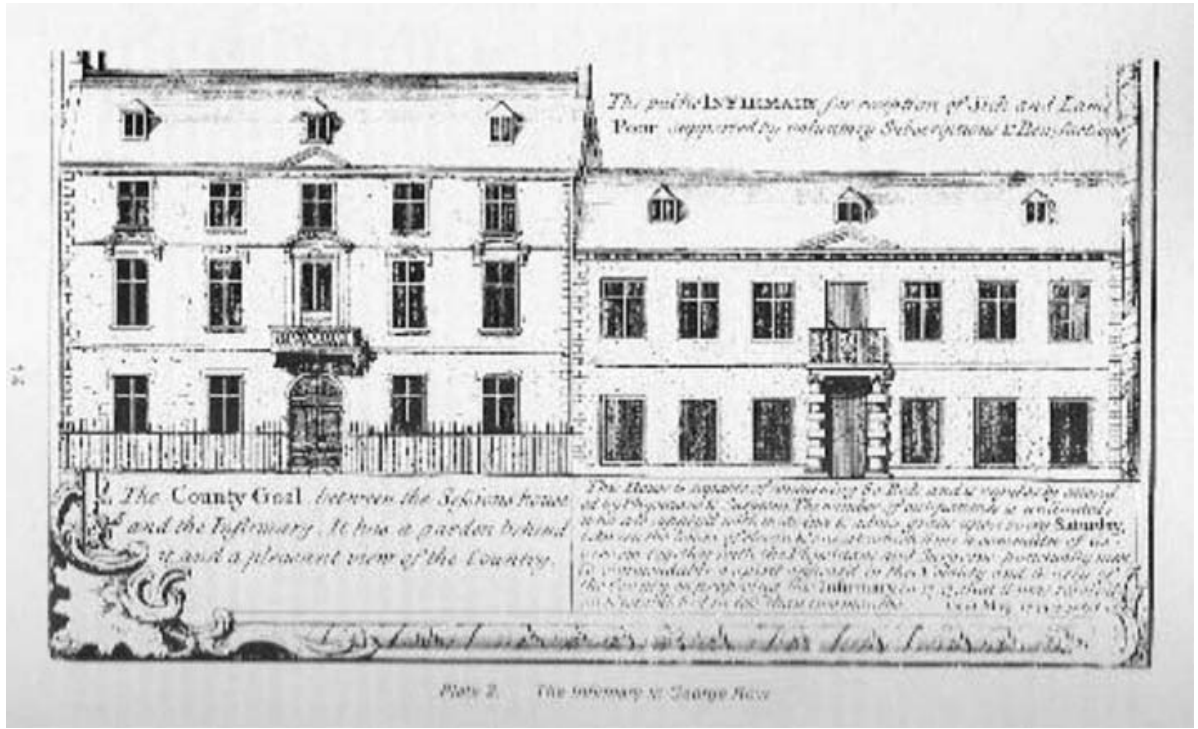

Figure 1 Contemporary print of the first Northampton General Infirmary.

recommendation of one of the Infirmary's benefactors first had to be sought. Patients were treated for nothing "and no money, gift or reward is taken of them or their friends on any account whatever". However, to prevent the hopelessly dying being cast into the wards, and the attendant funeral expenses being borne by the Infirmary, "caution money" was applied through the following rule: "No inpatient be admitted until 15/- is deposited to defray the expenses of burial in case he die, which shall be repaid if he be discharged deducting expenses".?

A report from the minutes of 1746 related that the weekly cost of drugs was about on average 9 pence. Every inpatient was calculated to stay for about 12 weeks, with the entire weekly cost per patient being 6 shillings.

The wards were very basic at the time. Light was produced by candles, heat from a coal fire, and the absence of any system of sewage meant that faecal and other waste was taken from the chamber pot into a tub in the corner of the ward, which was emptied by the appropriately titled "night man". ${ }^{7}$ It therefore comes as no surprise to read that on 22 June 1746 Dr Stonhouse, the attending physician, complained that the wards needed ventilating. He recommended three times a day using "a whirling windmill".

The medical staff were two physicians, a surgeon extraordinary, a house surgeon "who shall constantly reside in and have the general care of all the patients in the hospital", an apothecary, a secretary, and a matron.

The ward regime was very different from today. Patients were expected to help the nursing staff and also had to attend prayers every morning. Failure with the latter would lead to discharge from the ward "for irregularity" and readmission would not be allowed. ${ }^{7}$

But what of the paediatric cases seen during this period? These are the earliest English eighteenth century records that contain the patient's age (see tables 1 and 2 on the $A D C$ website; http://www.archdischild.com/supplemental).

The majority of the patients admitted were, as expected, adults, but nevertheless the records do show that children were treated, the majority of these as outpatients. Paediatric cases up to and including those 16 years of age made up 26\% (60/230) of the number of patients seen in the first year. However, in the eighteenth century we must bear in mind that children were considered adults from the age of 10 years. ${ }^{10}$ Within the first year of opening for children of 10 years of age and under, there were eight inpatient admissions, and 18 children were treated in outpatients. Outpatient cases include "fever", "asthmatick", "epileptic fits", and "incontinence of urine". It is a historical echo relevant to present day paediatric practice, that the discharge record for the cases of fever and leprosy was "cured",
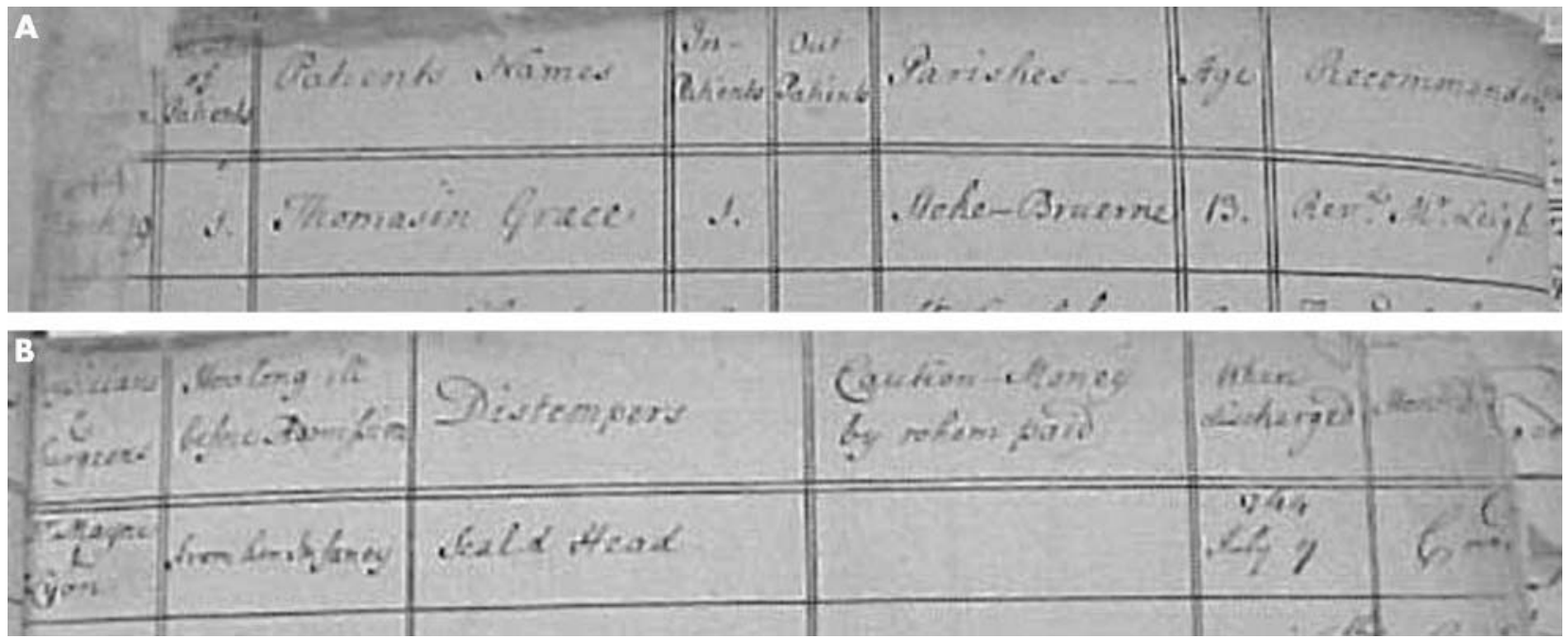

Figure 2 The admission record for Thomasin Grace. 
the asthmatic "relieved", but for the patients with epilepsy and incontinence, "incurable". The outpatient children's ages are younger, with children as young as 2 years being seen. The inpatient children are older, with most conditions reflecting some chronic infection, including for "rheumatism" or "fever". One is also struck by the length of time the patients had suffered prior to being seen. A short waiting time was most unusual, and the most extreme was Eliz Welch, a 16 year old girl who had suffered from "scorbutick eruptions" for the previous 12 years. Unfortunately no details of the treatment given are recorded and none survive from elsewhere. Thus these cases, although of great interest, have limited medical reliability, especially as over 250 years there have been profound changes in disease nomenclature as well as variations in how practitioners make their diagnosis.

I am not aware of any other hospital of this period having a child as their first patient. Unfortunately the original rules for Northampton General Infirmary have been lost, but it is almost certain that the admission of children was deliberately restricted as for other voluntary hospitals. An example of this is seen with the earliest surviving regulations of the Leicester Royal Infirmary (1778), which stated that "no child under six years of age, unless in extraordinary cases as fractures or where cutting for some stone of any operation is required shall be admitted as an inpatient". ${ }^{11}$ One of the reasons was that children under 7 were felt to be highly infectious and would be better managed at home. ${ }^{10}$ In Northampton, in its first year of operation, children as young as 2 years of age were seen in outpatients and from 8 years were admitted. This pattern was also seen in Birmingham when the hospital opened in 1779. Thus in spite of these rules, children somehow still slipped in.

Eventually, increasing demand for beds led to prolonged periods when the hospital would be full for new admissions. A new hospital was built on a new site and opened in 1793. It is this building which has been added to over the subsequent two centuries.

\section{CONCLUSION}

The history of child health in the United Kingdom does not start or culminate in the founding of specific hospitals dedicated for children. Rather it was an ongoing and evolving process dependent on the social mores, which allowed voluntary hospitals to thrive and prosper. Northampton General Hospital, as indeed is the case with most hospitals in the United Kingdom, is still evolving.

The work of Thomas Coram and his Foundling Hospital, founded to prevent deliberate "exposure", is contemporary to that of Northampton, but running parallel to it.

Northampton was typical of other hospitals founded in the eighteenth century, but clearly one could expect some difference in paediatric admissions to be seen over time, depending on later industries and local waterways, among other factors. Nevertheless, it is clear that in spite of regulations prohibiting their admission beyond defined criteria, children were treated as inpatients. We can only speculate as to the general treatments that they were given as no other records have survived.

Generally speaking, the success of the provincial hospitals was necessary to pave the way eventually to the successful founding by public subscription of children's hospitals, such as Great Ormond Street in 1852 onwards, and where already extant, the construction of specially designated children's wards, such as at Northampton in 1887.

Medical conditions in the United Kingdom today are very different from those of the eighteenth century, with infant mortality then breathtakingly high in comparison to that which we are familiar with. Dr Hugh Smith, a London eighteenth century contemporary author of The Family
Physician, put this figure at nearly two thirds of children born within London and its environs dying before the age of 5 years. ${ }^{12}$ It should also be noted that these records regarding admissions do not relate to antenatal and perinatal care, which would today fall under child health care. Indeed for the eighteenth and for most of the nineteenth centuries, "voluntary hospitals were dangerous places to have a baby". ${ }^{13}$

Later on, there followed a profound change regarding these grim statistics, and the public changed their opinion regarding this matter. However, it is of concern that at the time of writing this article, with the majority births now being in hospital, the increasing prevalence of acquired ward infections, such as methicillin resistant Staphylococcal aureus (MRSA), is undermining public confidence. ${ }^{14}$

Those pioneering medical and social predecessors, known and unknown, who by their unstinting efforts achieved this substantial and sustained reduction, command our respect.

Evans and Redmond Howard summarised the ongoing relevance of an understanding of the past:

\section{"For half the romance of the hospital movement consists in the fact that its 'peaceful battles', realised by only very few, are greater than those of war: for of what campaign in our history could it be said that it had saved half the infant population of England."}

This could not be more relevant when we consider the current disgrace in the developing world of the annual waste of millions of children's lives through utterly preventable disease.

\section{ACKNOWLEDGEMENTS}

The chance discovery of an extremely rare copy of John Darwall's Plain Instructions for the Management of Infants (1830) within the Northampton General Hospital archive led to this paper. I would like to thank the staff at the Northamptonshire County Record Office, the Library, Cripps Medical Centre, Northampton General Hospital, for their assistance and Dr Margaret Holloway, Dr Jonathan Reinarz, and Mrs Sarah-Jane Leatherland for their advice.

Let us hope that these and other hospital records are safely preserved, so future child health professionals and medical historians hearing their voices, will learn and be inspired by them.

\section{Competing interests: none declared}

\section{REFERENCES}

1 Porter R. The greatest benefit to mankind a medical history of humanity from antiquity to the present. London: Harper Collins, 1997:382-3.

2 Porter R. Enlightenment. Britain and the creation of the modern. London: World Penguin Books, 2001:206-7.

3 Granshaw L. The hospital. Chapter 49. In: Bynum B, Porter R, eds. Companion encyclopaedia of the history of medicine. 1993:1185.

4 Waddy FF. A history of Northampton General Hospital 1743-1948. Northampton: The Guildhall Press, 1974:4-10.

5 Dunn PM. George Armstrong MD (1719-1789) and his dispensary for the infant poor. Arch Dis Child 2002;87:228-31.

6 Markham CA. A history of the Northampton General Hospital, Northamptonshire. Notes and Queries 1907;2:2.

7 Waddy FF. A history of Northampton General Hospital 1743-1948. Northampton: The Guildhall Press, 1974:31.

8 Markham CA. A history of the Northampton General Hospital, Northamptonshire. Notes and Queries 1907;2:3-12.

9 Waddy FF. A history of Northampton General Hospital 1743-1948. Northampton: The Guildhall Press, 1974:5.

10 Reinarz J. Healthcare and the second city. The development of the Birmingham teaching hospitals in the nineteenth century. Birmingham Historian 2004:21.

11 Frizelle ER. The life and times of the Royal Infirmary at Leicester. The history of a teaching hospital 1766-1980. Leicester University Press, 1978:403.

12 Smith H. The family physician. Introduction cited in Still GF. The history of paediatrics (1932) (reprinted College of Paediatrics and Child Health, London, 1996:455)

13 Loudon ISL. Childbirth. Chapter 44. In: Bynum WF, Porter R, eds. Companion encyclopaedia of the history of medicine. 1993;2:1056.

14 Revill J. Mothers clean wards to keep babies safe. The Observer, 5 June 2005.

15 Delbert Evans A, Redmond Howard LG. The Romance of the British Voluntary Hospital Movement. London: Hutchinson \& Co, 1950:159-62. 